\title{
Discurso e sentido nas campanhas publicitárias sobre "doenças tropicais" transmitidas pelo Aedes aegypti
}

\section{| ${ }^{1}$ Anderson de Carvalho Pereira |}

Resumo: $\mathrm{O}$ artigo apresenta resultados da investigação sobre as estratégias de interpretação pelas quais campanhas publicitárias delimitam um lugar discursivo ao sujeito-preventivo das doenças tropicais transmitidas pelo Aedes aegypti. Para isto, mobiliza conceitos da Análise de Discurso francesa, principalmente os conceitos de formaçóes imaginárias, ideologia e posição-sujeito. Filiado ao paradigma indiciário de análise, o estudo analisa cinco imagens e enunciados veiculados nestas campanhas e mostra que o lugar do sujeito-preventivo é marcado pela culpabilidade individual, por meio de uma lógica disjuntiva sobre a responsabilidade tanto ao espaço privado quanto à esfera pública que ignora a conjuntura sociopolítica mais complexa de seu entorno.

> Palavras-chave: doenças tropicais; Aedes aegypti; promoção da saúde; saúde pública; campanha.

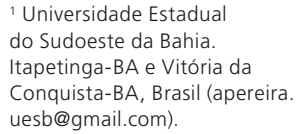

Recebido em: 30/06/2017 Aprovado em: 31/10/2017 


\section{Introdução}

A epígrafe roseana mostra que é impossível não acreditar nos estragos provocados pela transmissão do "bichinho amaldiçoado" (qualquer que seja) transmitido por um mosquito do cerrado, do sertáo, da caatinga, da floresta, ou de qualquer outra parte do mundo tropical. Em um período recente, vimos no cenário brasileiro o aparecimento intenso de campanhas publicitárias voltadas ao combate ao Aedes aegypiti na prevenção à dengue, à febre chikungunya e ao zika vírus.

Várias publicações têm demonstrado fatores interacionais ligados às infecções, mas poucas têm investigado condutas de prevenção da população, bem como dos agentes de saúde atreladas aos aspectos da linguagem no intercâmbio de informaçôes entre a população em geral e as esferas governamentais. $\mathrm{Na}$ base SciELO, por exemplo, encontra-se apenas um estudo (LENZI; COURA, 2004) cujo foco versa sobre os conteúdos informativos das campanhas. De outra perspectiva, neste estudo, enfocamos aspectos discursivos na linha do estudo já realizado por Souza et al. (2012).

Muito também se tem investido nas valiosas pesquisas de laboratório para a confecçáo de vacinas e medicamentos eficazes, mas pouco se tem discutido acerca do jogo de interpretaçáo deste universo simbólico em que se trata de problemática inerente ao modo de se relacionar com o outro, de se interpretar a relação indireta entre homem, linguagem e realidade.

Parte deste dinamismo interpretativo se espraia em uma rede de sentidos sobre "saúde", "prevençáa", "doença", que muitas vezes parece claro e transparente, mas indica uma opacidade em uma esfera específica da estrutura da linguagem. A partir desta opacidade e da não transparência da interpretação pressupostas na perspectiva discursiva aqui adotada, uma vez que nunca se veicula um único rumo para o sentido acerca de um "tema", propomos analisar do ponto de vista linguístico-discursivo os mecanismos discursivos da construção de um interlocutor a quem se dirigem campanhas publicitárias sobre "doenças tropicais" transmitidas pelo Aedes aegypti. Esta análise inclui uma discussão sobre a reversibilidade das posiçóes discursivas ocupadas ou a serem ocupadas conforme a veiculaçâo dos sentidos. 
Para isto, tomamos como objeto de análise campanhas publicitárias de natureza vária (incluindo as veiculadas pelos governos federal, estadual e municipal, bem como imagens de outras entidades que circulam na web) resultantes de campanhas do período de 2013 a 2016. Em meio a um campo mais amplo dos sentidos, o da denominada "doença tropical", sobretudo, em seu aspecto preventivo, focamos a busca de campanhas publicitárias voltadas às principais doenças comumente aceitas na comunidade científica como decorrentes da transmissão pelo Aedes aegypti.

O início da análise indica que "prevenir" já nos indica uma tentativa da campanha antecipar um lugar de interpretação, o que a nosso ver pode ser discutido pelo conceito de imaginário. Retornaremos a este conceito.

Partindo do pressuposto de que há uma engrenagem semântica atravessada por mecanismos ideológicos determinados politicamente, apostamos que a Análise de Discurso francesa pecheutiana (doravante, AD) oferece uma alternativa para trilhar a rede de sentidos que organiza posiçóes deste sujeito do discurso da "prevenção", fomentando o debate sobre o jogo imaginário em torno de prevenção, saúde, doença, culpabilidade, etc. Partimos também do pressuposto de que é no jogo com os sentidos (interpretação) que a ciência também é um lugar político.

Em meio a estas indagaçóes, campanhas publicitárias foram capturadas da web e analisadas conforme o paradigma indiciário de análise e a proposta de análise discursiva pecheutiana, a serem explicados adiante. A análise segue os pressupostos destes referenciais teóricos, bem como a continuidade de um campo de investigação sobre a materialidade discursiva da campanha publicitária e o uso de imagens na sociedade do espetáculo, tal como já realizamos em outros trabalhos (PEREIRA, 2016; TFOUNI; PEREIRA, 2016). Sendo assim, propomos uma leitura do lugar (no imaginário) em que é colocado o "sujeitopreventivo" (expressão nossa) das doenças transmitidas pelo Aedes aegypti e perguntamos: que lugar é este? De que modo, o jogo de sentidos sobre o espaço privado da "casa" em oposição à rua e à esfera pública delimita este lugar?

A partir disso nosso objetivo principal é investigar qual o lugar discursivo (marcado no imaginário) do sujeito responsabilizado pela campanha publicitária a prevenir a transmissão do Aedes aegypti. Para isso, faz-se necessário apresentar os conceitos de discurso, sentido, imaginário, bem como as estratégias metodológicas de natureza indiciária utilizadas nesta pesquisa. 


\section{"Doenças tropicais": um espaço polêmico por excelência}

Ao analisar a polêmica em torno do debate sobre o valor do predicado clima em torno de algumas doenças, Camargo (2008, p. 96) explica que historicamente se levou a acreditar que "nas doenças tropicais, há certamente um forte componente de subdesenvolvimento, consequência tardia do colonialismo, mas há também certa fatalidade tropical, consequência da heterogeneidade das evoluçóes geológica e biológica". Por esta via, o autor acredita que:

Sob esse prisma, as duas posiçóes conflitantes sobre as raízes das "doenças tropi-
cais" fortalecidas no início do século XX em realidade não são antagônicas, mas se
complementam: fatalidade biogeográfica e subdesenvolvimento são os genitores das
"doenças tropicais". Aliás, há doenças que, não fosse o subdesenvolvimento, não mais
existiriam atualmente. (p. 108).

Sem nos aprofundarmos na revisão histórica pautada pelo autor, vemos por esta caracterização que o componente sócio-histórico e político é premente ao debate sobre doenças tropicais nas quais se podem incluir as relacionadas à transmissão pelo vetor Aedes aegypti (transmissor de dengue, chikungunya e zika). Dentro deste prospecto, o modo como se acredita ser uma forma possível de se relacionar com o aparato simbólico ligado a uma doença específica ou a um grupo destas, depende de como lhe são atribuídos sentidos, sentidos estes construídos social e historicamente.

Correa (2013), por sua vez, explica como jornais alemães construíram um modo de leitura sobre combate às "doenças tropicais" para o público "leigo", composto de migrantes e seus descendentes no Brasil. Isto ocorreu porque a medicina tropical foi uma ferramenta política do colonialismo o que aparece em vários documentos que apontam a preocupação do segundo Reich com sua eficácia. Entre o uso predominante de ervas da medicina popular, o migrante convivia com os saberes locais pois somente nos grandes centros como Rio de Janeiro e Sáo Paulo se consolidaria uma medicina tropical pela tentativa de identificar problemas supostamente ligados ao subdesenvolvimento.

A reboque desta crença, viriam os debates da geografia, da etnografia e da antropologia; foi assim que o volume de narrativas enviadas à Alemanha sobre as baixas nos exércitos e os interesses na preservação do corpo do nativo africano para máo de obra alavancou o investimento na ciência tropical, incluindo-se 
a tentativa de acelerar obras de infraestrutura com a diminuição da baixa nos grupos de trabalhadores (CORREA, 2013).

A nosso ver, a circulação e divulgação de informaçóes pela imprensa envolvia, como podemos notar pela análise de Correa (2013), uma leitura, um modo de interpretar e um modo de interpelar sujeitos envolvidos à questão, que lhes delimitou um lugar. Como o autor faz notar, estaria nesta leitura "A chave para a África em mãos alemãs" (p. 86). A interpelação é, segundo Pêcheux (1993), um modo de constituir o sujeito, de tornar evidente o mecanismo de designação “eu sou”, pelo qual um lugar da interpretação está sujeito (destaque nosso) a um sentido e não a outro.

Este nosso olhar está em sintonia com Barros (2006, p. 297) para quem “o olhar estrangeiro sobre os trópicos está muito além da nossa compreensão. Afinal, à medida que somos foco do seu olhar nos transformamos, também, em estrangeiros, sob os olhos de quem chega". Por acreditarmos que a presença do Outro na familiaridade e a estranheza podem conviver mergulhados no "mesmo", no comum das açōes cotidianas, no "mesmo" universo simbólico do qual os sujeitos acreditam nunca desgarrar, ratificamos o mesmo autor também quando comenta que "uma mesma visão pode ter distintas representatividades, o que ocorreu justamente com relação à imagem dos trópicos” (p. 297).

Sem complacência nestas representatividades, diz Barros (2006), esta discussão resgata o valor político do Jeca Tatu e de várias obras clássicas como Rosa, já citado em nossa epígrafe, Graciliano Ramos e Euclides da Cunha. Mas o que mais nos interessa é a sintonia com o destaque do autor para o fato de que a nomeação “doenças tropicais ou exóticas” está atravessada pelo olhar, por uma leitura colonizadora dominadora, atribuindo culpa individual e apagando a relação do adoecimento com a degradação ambiental enredada por um jogo de força político complexo e constante; por um jogo político, acrescentamos, em que as posiçóes são definidas pelo jogo com os sentidos que obrigatoriamente resgatam esta anterioridade sócio-histórica e define um modo de interpretação veiculado em campanhas publicitárias de prevenção.

Por este caminho, queremos mostrar que a posição-sujeito sustenta a evidência de que o Outro o define em um lugar e apaga as possibilidades de ocupar outros lugares no jogo com a linguagem e com as açóes simbólicas no mundo. É este jogo que nos obriga a tratar do conceito de imaginário e de posição-sujeito. 


\section{O conceito de imaginário}

Desta discussão, percebe-se que a prevenção marca o sentido de uma antecipaçáo que se teria para o sujeito em um lugar determinado na estrutura da linguagem. A expectativa de que o outro interceda em uma rede de sentidos em uma dada posição tem relação com uma leitura (interpretação) prévia que acerca deste sujeito é feita e que pode ser explicada pelo conceito lacaniano de imaginário. Já haveria um lugar antecipado sujeito a uma interpretação específica. É isto que nos permite uma aproximaçáo com o conceito de imaginário, tal como entendido por Lacan (1998), como um dos registros do sujeito; e, tal como presente na AD, para explicar de que maneira em função da identificaçáo imaginária um lugar se torna sujeito a uma interpretação e não a outra.

O imaginário é o lugar da dúvida, da incerteza, da lacuna a ser preenchida por sentidos já dispostos no simbólico (o registro da relação entre parte e todo; entre universais e particularidades) e que parte de apostas, de tentativas de antever um lugar "mais adequado" antes mesmo do sujeito vir a ocupá-lo. Além disso, o imaginário tem que se haver com o fato de que a mensagem que vem do Outro e que constitui a relação entre sujeito, linguagem e mundo é invertida por excelência; e por isso também enigmática, cifrada e a ser interpretada. Neste jogo incessante, incompleto e pouco definido, a marcaçáo de uma posiçáo torna-se em grande medida ilusória e provisória, uma vez que mistura realidade e ficção e que também muda constantemente (AULAGNIER, 1979; LACAN, 1998; VANIER, 2005).

Ressaltamos que o conceito de imaginário resvala nas discussóes de Lacan (1998) acerca da paranoia, desde o início de sua carreira. Não se trata do cerco da Psicopatologia, mas de um lugar para o modo de constantemente nos atermos ao olhar do outro no cotidiano. A interpretaçáo espraiada no modo de interpretar e ser interpretado pelo olhar do Outro, pelo campo da atribuição de sentidos já estabelecidos por um campo simbólico e ao mesmo tempo em aberto, porvir. Rarefeito e firmado em posiçôes. Conforme Cabas (1982, p. 20, grifos do autor): "deste modo, quem diz imaginário, diz imagem e quem diz imagem pode dizer espelho e rede. Mas também é certo que quem diz imagem pode querer dizer ilusão".

No campo da denominada saúde preventiva, as campanhas publicitárias ocupam um desses modos do grande Outro (que na Psicanálise lacaniana se enquadra uma discussão sobre o valor simbólico do Nome-do-Pai) atribuir nome, lugar, posição. Ocorre que a posição pode ser marcada por uma ausência real 
que mesmo assim não interrompe a produção de sentidos, de direcionamentos metafóricos para um lugar assujeitado.

É por meio destas subversóes, destas reviravoltas do sentido disfarçado no jogo entre a superficialidade linguística e o que a antecede que se engrenam as redes de sentido. Trata-se, antes de tudo, de uma engrenagem em parte falha e em parte incompleta (HENRY, 1992) e que sempre indica um lugar possível para o sujeito, em meio à imagem que o Outro lhe indica como único lugar a ser ocupado; esta ilusão de exclusividade pode dar lugar a um lugar singular.

Ocorre que esta expectativa e este assinalamento de um lugar é atravessado pelo jogo de poder político em que a aparência de única possiblidade mascara a artificialidade no jogo com o poder do direcionamento do olhar sobre o outro, pelo corpo e pela unidade ilusória do indivíduo liberal moderno (HAROCHE, 1992; PÊCHEUX, 1993).

A decifração de parte desta rede de sentidos envolvida no jogo de posiçóes veiculadas pela campanha publicitária de prevenção ao Aedes aegypti é o que nos leva a tratar mais de perto o conceito de posição-sujeito do discurso.

\section{O conceito de posição-sujeito do discurso}

Derivado da reflexão mais ampla e complexa sobre a natureza do sentido e sobre o valor sociopolítico do discurso científico, o conceito de posição-sujeito em Pêcheux (1993) também resulta de uma discussão sobre o que antecederia qualquer forma do dizer em uma estrutura mais ampla da linguagem. Filiado ao pressuposto das teorias do discurso de que qualquer forma do dizer comportaria um "já dito", uma anterioridade que pressupóe uma direção anteposta a uma interpretação, o autor também debate acerca da natureza velada e opaca do que aparece em uma superficialidade linguística.

O retorno de uma evidência e de uma problematização com a natureza do sentido é a condição para uma tomada de posição do sujeito. Ocorre que esta tomada de posição ocorre por retroação, por meio de um exercício de interpretação na cadeia significante e que é um jogo político.

Diferentemente da crença alimentada pela ciência dominante de que não se trabalha por meio de qualquer atitude simbólica com interpretação, a tomada de posição não é também uma escolha individual, é uma asserção atravessada pela dúvida (no nível do imaginário) que determina que o interdiscurso (a rede de 
sentidos que atravessa qualquer dizer) sofre o efeito de uma "exterioridade", ou seja, do fato de que a realidade é ideológica e discursiva e, assim, a todo tempo "se volta sobre si mesma” (expressão de PÊCHEUX, 1993, p. 166).

Trata-se e um movimento sempre dialético em que as redes de sentido mais amplas que amparam a possibilidade de assunção de um lugar sujeito à interpretação sempre retornam por meio do efeito ideológico elementar de que "eu falo" e não o "outro", à medida que apaga do sujeito parte do "mesmo" sujeito que fala.

\section{Método}

Ao nos darmos conta, pela observação e o estranhamento diante da profusão dessas imagens, de que haveria um "padrão" na veiculação de discursos acerca da prevenção às "doenças tropicais" transmitidas pelo Aedes aegypti, formulamos nossa questáo sobre quais seriam os mecanismos discursivos envolvidos na responsabilizaçáo individual e o apagamento da presença dos governos e do cumprimento coletivo de políticas públicas voltadas a este campo. Ao nos recordarmos de alguns períodos de maior incidência de campanhas publicitárias (como as epidemias de 2005 e 2006; e de 2013 a 2015), buscamos na web algumas dessas imagens.

Em seguida, a interface de nossa análise discursiva com o campo semântico das "doenças tropicais" se deu, uma vez que as campanhas publicitárias coletadas pareciam pressupor a nosso olhar inicial um interlocutor a ser informado, que em tese não disporia de saber legítimo e acessível. Além disso, em uma primeira busca, a nosso ver, as que supunham um interlocutor. Esta familiaridade com o "já dito" sobre "doenças tropicais", num gesto de mobilizaçâo de uma evidencia, evidencia esta problematizada acima neste artigo, levou-nos a continuar o debate proposto por Camargo (2008), Correa (2013) e Barros (2006).

Por este caminho, lançamos em conjunto no buscador Google as palavras: campanha; governo; dengue; zika; chicungunya;. Mesmo as que não tiveram marca de um governo (federal, estadual ou municipal) e que apareceram foram consideradas.

Apoiando-nos nos pressupostos de que há efeito de sentido (interpretação) nos discursos do cotidiano em que o sujeito aparece como lugar sujeito à intepretação (PÊCHEUX, 1997) e em que o intérprete provoca movimentos de antecipação, retomada e reformulação no imaginário além da premissa de que há uma eficácia material do imaginário (PÊCHEUX, 1993) que faria o interlocutor acreditar em 
uma culpabilidade individual criamos um dispositivo de análise principalmente baseado no conceito de imaginário.

Para a análise, foram utilizadas as noçóes de que em $\mathrm{AD}$ o dado não é uma marca empírica a ser testada, mas fragmento de discursos que o atravessa para um debate de natureza interpretativa (ORLANDI, 2001). Conforme o paradigma indiciário, relido por Tfouni (1992), o "dado" é um indício que desfaz a separação que haveria entre sujeito e o objeto e permite uma análise inserida no campo mais amplo da estrutura da linguagem.

\section{Resultados e discussão}

Seguemse as imagens e enunciados capturados de campanhas publicitárias sobre o Aedes aegypti e a respetiva análise.

Figura 1. DENGUE Faça sua liçáo de casa. Água parada dá dengue (Campanha publicitária veiculada pela coordenação de vigilância em saúde - COVISA - da Secretaria de Saúde da Prefeitura da cidade de São Paulo. 2013) ${ }^{1}$

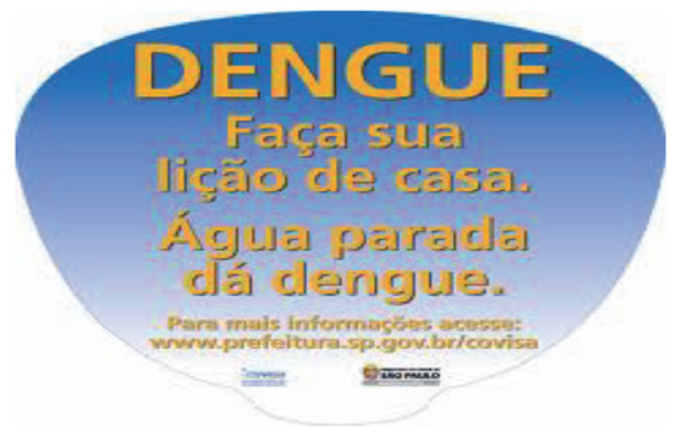

Figura 2. Não crie mosquito pra te morder. Dengue mata² (Campanha publicitária veiculada pela Secretaria de Saúde - Governo da Bahia, 2013)

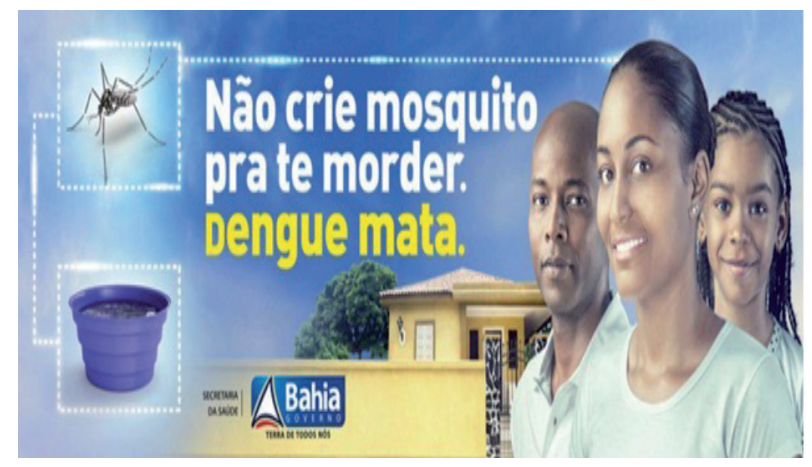


Figura 3. DENGUE CHIKUNGUNYA ZIKA VÍRUS. A responsabilidade de combater é sua e a vida é pra todos ${ }^{3}$ (Campanha publicitária veiculada pela Prefeitura de Cacoalzinho de Goiás, 2016)

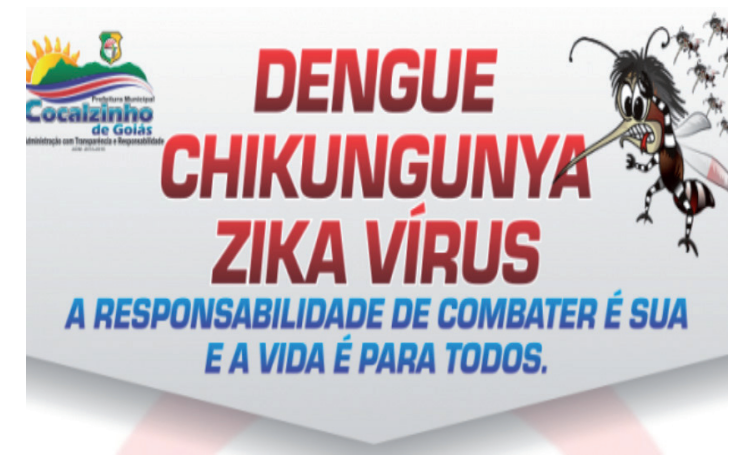

Figura 4. DENGUE CHIKUNGUNYA \& ZIKA. Não deixe eles fazerem sucesso no seu quintal. ${ }^{4}$ (Campanha publicitária de ampla divulgação na web. Origem desconhecida)

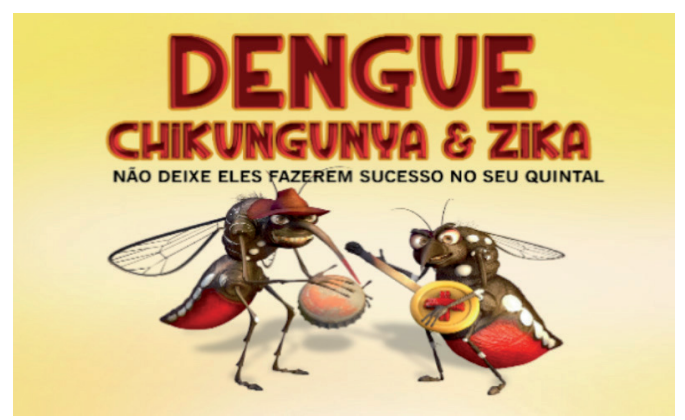

Figura 5. O AEDES AEGYPTI TRANSMITE O VÍRUS DA DENGUE, ZIKA, CHIKUNGUYA E FEBRE AMARELA URBANA. ELIMNEO.\#OPROBLEMAÉSEU.UFRN ${ }^{5}$ (Campanha publicitária veiculada pela Universidade Federal do Rio Grande do Norte, 2016)

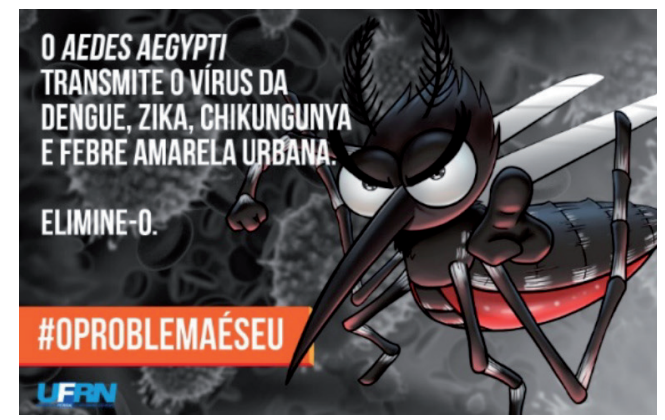


De modo geral, defendemos que as cinco imagens atribuem uma culpabilidade individual e interferem na possibilidade de múltiplas interpretaçóes, interferência esta que exige um trabalho de interpretação que começamos a apresentar.

É deste modo que funciona a evidência do enunciado na imagem 1, em que "faça sua lição de casa" naturaliza o sentido de que se trata de um "dever". Tratase de um modo de interpretar a realidade que "deve ser", "tem que ser" de uma maneira e não de outra. Parece impossível questionar esta evidência e apontar que esta deontologia náo possa ser ampliada por meio de um debate mais amplo sobre a complexidade da realidade da problemática.

Em todas as peças analisadas, chama a atenção o uso dos verbos no imperativo, indicativo de ordem, no sentido de mandonismo, herança no modo autoritário e na rigidez hierárquica no tratamento da esfera pública no imaginário brasileiro.

Mais especificamente, na segunda imagem temos o uso do pronome reflexivo, o que indica que a culpa por "morder" seria radicalmente individual. Nesta também vemos a paráfrase de alguns ditados populares, a saber: "arrumar sarna para se coçar"; "criar cobra para te picar". Estes enunciados têm efeito de genérico discursivo. O genérico é uma formulação enunciativa que funciona de forma semelhante à premissa maior de um silogismo e de modo hermético a outra interpretação possível (TFOUNI, 2010).

Na terceira imagem, por substituiçáo, "todos" retoma "sua" que também designa "todos". Se, ao fazermos esta análise do pressuposto, podemos afirmar que é repetido que a responsabilidade é de "todos" por que esta repetição opõe "vida" e "responsabilidade"? Ao analisarmos o enunciado, vemos que há um par como se houvesse oposição entre "vida" e "responsabilidade". Parece haver uma contingência; porém, enunciados sequenciados desta maneira não pressupõem necessariamente que devam ser interpretados numa lógica causal (cf. DUCROT, 1987).

Sobre o pressuposto nos enunciados, afirma Ducrot (1987, p. 20): "o pressuposto é o que apresento como pertencendo ao domínio comum das duas personagens do diálogo, como o objeto de uma cumplicidade fundamental que liga entre si os participantes do ato de comunicação".

Na imagem 3, vemos a oposição entre "sua" e "todos" após o verbo. O "sua" tem efeito genérico, pois indica que pode ser qualquer um. Pressupóe, portanto, que a responsabilidade é de todos (ou de ninguém?), uma vez que está pressuposto que "sua" serve para qualquer interlocutor possível na enunciação. 
$\mathrm{Na}$ quarta imagem, é levantada uma questão cara ao imaginário brasileiro. A dialética entre casa e rua. Além da naturalizaçâo do sentido de "sucesso" como algo que em tese todos querem alcançar, mesmo quando (como é o caso do enunciado) não se define o que se entende por sucesso, o uso de "no seu quintal" remete ao valor do uso privado de questóes de interesse público, como é o caso da "saúde". A saúde não é propriedade privada; faz parte do rol das discussōes sobre questôes de interesse público e coletivo, portanto, não pode ser localizada no espaço puramente privado, como se isso fosse possível. Nem se trata de um "problema que é seu" com designação individual, como aparece naturalizado no enunciado da quinta imagem, ao afirmar "\#OPROBLEMAÉSEU”.

Voltamos à evidência de que se trataria de uma problemática individual. $\mathrm{O}$ uso repetitivo do pronome reflexivo evidencia que a culpa pela transmissão dos agentes infecciosos seria do indivíduo que não cuida da própria casa (imagens 1,2 e 4), que cultiva o mosquito (imagem 2) e que ignora um problema que seria exclusivamente de si (imagem 5).

Em AD, a repetição é o lugar privilegiado para o analista (pesquisador) apontar que uma questão da esfera das "coisas a saber" - expressão de Pêcheux (1997) -, ou seja, que remetem à dimensão desconhecida que atravessa o imaginário tende a ser repetida para obturar alguma falha, no sentido da falta, do não poder dizer tudo, o que é feito por meio da evidência de que X é X. Em outras palavras, no caso, de que a "culpa" é exclusivamente individual.

Esta inflexão verbal mantém aliança com o campo semântico do cuidado de si como cuidado da casa. Por meio desta evidência, apagam-se as condiçóes de enunciação ligadas às questôes de compromisso coletivo. Existe uma anterioridade, um "já dito" como se denomina em $\mathrm{AD}$ acerca da relaçâo entre público e privado que ajuda a desalinhavar os sentidos em questáo.

DaMatta (1997) explica que, para o brasileiro, a rua designa imprevistos e acidentes. $\mathrm{O}$ forte padrão hierárquico da casa patriarcal contrasta com a imprevisibilidade das relaçôes na rua, devendo-se estar atento para náo violar um código de um grupo social. O desconhecimento pode levar a arriscar e ter que se haver com infraçôes. Sua discussão é herdeira da reflexão de Holanda (1995) sobre a violência no espaço público e o rígido padrão das hierarquias, no período colonial, fortalecida no meio rural e incipiente no meio urbano. 
Desta discussão interessa-nos notar que o continuum entre casa e rua estabelece

também continuidade entre o plano da casa e o plano das cidades. É o que explica o valor da expressão "minha (ou nossa) rua” (p. 93). É neste lugar do imaginário que exploramos a análise destas campanhas publicitárias.

Os simbolismos das condutas em ambos os espaços refletem nas posiçóes sociais. Por exemplo, "botar para fora de casa" é aniquilar uma posição social; violentar alguém pode ser uma atitude comportável ao espaço privado da casa (DAMATTA, 1997) e que remete no mundo latino à autorização pública para a violência privada entre o período feudal e a Renascença europeia (DUBY, 1994).

Atravessado por esta dialética, todo o simbolismo da casa é herdeiro do simbolismo do corpo; deste modo:

Dormir, comer, banhar-se ter relaçóes sexuais e todos os outros modos de obter satis-
façáo ou alívio fisiológico são ações que devem ocorrer no universo da casa, onde as
pessoas se recuperam e se renovam do desgaste cotidiano. Tudo, pois, que remete ao
uso, cuidados e recuperaçáo do corpo - e que, como consequência implica descanso e
renovaçáo - está ligado ao mundo doméstico. (DAMATTA, 1997, p. 95).

Mas se pensarmos na rua, neste prospecto da gradação hierárquica, como uma grande "casa governamental" (expressão nossa), onde estão autorizados, conforme esse autor, a ocorrer os grandes debates políticos, cabe perguntar: como interpretar a atribuição feita por todas estas peças de campanha publicitária à responsabilidade individual? Que lugar é este que transforma este continuum numa dicotomia?

Pelos operadores linguísticos utilizados (a saber: "não crie"; "a responsabilidade é sua", "não deixe", "elimine-o") na voz imperativa e por pronomes reflexivos, percebemos que os enunciados analisados impóem uma lógica disjuntiva; por serem assim formulados, impóem a dicotomia: ou se trata da casa ou se trata do espaço público. No caso, essas vozes imperativas impóem o cuidado individual com a casa, atribuindo culpabilidade reduzida ao âmbito individual.

No entanto, o que está apagado nas condições de produção desses enunciados é quem seria o responsável pelo cuidado com o espaço público. Atua nas condiçôes de interpretaçáo disponibilizadas ao interlocutor que, apesar de lhe atribuir uma responsabilidade individual, o lugar ocupado pelo porta-voz do Estado estaria autorizado a apagar o compromisso coletivo com o cuidado preventivo. Deste modo, atua um "já sabido" que remete ao Brasil colonial e que designaria o espaço 
público como "terra de ninguém”. É a herança no imaginário, por exemplo, do desprezo pelas tinas de dejetos carregados pelos escravos.

Deste modo, esta evidência se filia a uma rede sócio-historica mais ampla que remete à crise habitacional, o afã paisagístico europeizado e as epidemias do fim do Império e início da República, incluindo mudanças na cartografia feitas pela classe médica e campanhas sanitárias drásticas em meio a um viés autoritário de "ordem" urbana (PATTO, 1999).

Com os seguintes interesses, segundo Patto (1999, p. 178):

[...] a obsessão ordeira desencadeada pelo medo antigo e crescente que as classes dominantes tinham da revolta popular, potencializado pelos protestos de rua e pelo aumento das estatísticas criminais; o propósito sincero de alguns de enfrentar a gravidade real das condiçôes sanitárias das cidades atingidas periodicamente pela peste; os interesses do capital comercial e financeiro internacional. Mas, no caso brasileiro, a campanha higienista esteve sobretudo a serviço de dois projetos da classe dominante: superar a humilhação frente ao "atraso" do país em relação aos "países civilizados", pela realização do sonho provinciano de assemelhar-se à Europa, e salvar a nacionalidade pela regeneração do povo.

Por este caminho da interpretação, constrói-se no imaginário o lugar de um "sujeito-preventivo" que apenas obedece, executa e deve ter plena clareza do espaço privado, mas, no entanto, não tem que se haver com um compromisso coletivo, uma vez que o próprio lugar que autoriza sua conduta é um lugar vazio de marcas comprometidas com esta coletividade. Este jogo político complexo no imaginário nacional nos leva a indagarmos com DaMatta (1997, p. 101) sobre algo crucial sobre o compromisso coletivo: "quando se pode modificar o mundo doméstico ou o mundo público, seja transformando um desses domínios ou outro, seja enfatizando apenas uma deles"?

\section{Conclusóes}

Pela análise da campanha publicitária situada no imaginário das "doenças tropicais" provocadas pela transmissão do Aedes Aegypti, vemos que há um jogo de interpretação amparado pela interlocução construída na veiculaçáo de campanhas publicitárias.

Por meio destas, há a tentativa no imaginário de impor uma apropriação individual no lugar do que é de interesse público (saúde). Deste lugar no imaginário se constrói uma posição-sujeito "preventivo" que apaga o caráter dialético do jogo político entre público e privado e faz parecer que se trata de uma questão 
meramente individual. Possíveis decorrências deste jogo de sentido no nível do imaginário são: a precariedade do cuidado com o espaço público e o descaso com açóes de interesse e compromisso coletivo. Acreditamos que, amparadas por outros mecanismos de interpretação, podem trilhar caminhos menos simplistas ao enfrentamento das epidemias transmitidas pelo Aedes aegypti.

\section{Referências}

AULAGNIER, P. A violência da interpretação. Rio de Janeiro: Imago, 1979.

BARroS, M. Clima e endemias tropicais. Estud. Av. São Paulo, v. 20, n. 58, p. 297-306, dez. 2006.

CABAS, A. G. Curso e discurso na obra de Jacques Lacan. São Paulo: Moraes, 1982.

CAMARGO, E. P. Doenças tropicais. Estud. Av. São Paulo, v. 22, n. 64, p. 95-110, dez. 2008.

CORREA, S. M. S. O “combate” às doenças tropicais na imprensa colonial alemã. Hist. cienc. saude-Manguinhos. Rio de Janeiro, v. 20, n. 1, p. 69-91, mar. 2013.

DAMATTA, R. A casa e a rua. In: Carnavais, malandros e heróis: para uma sociologia do dilema brasileiro. Rio de Janeiro: Rocco, 1997. P. 90-102.

DUBY, G. História da vida privada 2: da Europa feudal à Renascença. São Paulo: Cia das Letras, 1994.

DUCROT, O. O dizer e o dito. Campinas: Pontes, 1987.

HAROCHE, C. Fazer dizer, querer dizer. São Paulo: Hucitec, 1992.

HENRY, P. A ferramenta imperfeita: Sujeito, língua, História. Campinas: UNICAMP, 1992.

HOLANDA, S. B. Raizes do Brasil. São Paulo: Cia das Letras, 1995.

LACAN, J. O estádio do espelho como formador da função do eu. In: Escritos. Rio de Janeiro: Zahar, 1998. p. 96-103.

LENZI, M. F.; COURA, L. C. Prevenção da dengue: a informação em foco. Rev. Soc. Bras. Med. Trop. Uberaba, v. 37, n. 4, p. 343-350, ago. 2004

ORLANDI, E. P. Interpretação: autoria, leitura e efeitos do trabalho simbólico. Petropolis: Vozes, 2001.

PATTO, M. H. S. Estado, ciência e política na Primeira República: a desqualificação dos pobres. . Estud. Av., São Paulo, v. 13, n. 35, p. 167-198, abr. 1999.

PÊCHEUX, M. Discurso: estrutura ou acontecimento? Campina: Pontes, 1997. . Semântica e discurso: uma crítica à afirmação do óbvio. Campinas: UNICAMP, 1993.

PEREIRA, A. C. Memória discursiva e ideologia: uma análise da propaganda dos grandes eventos esportivo do Brasil Contemporâneo. Intertexto, Uberaba, v. 9, n. 2, p.1-17, 2016. 
1240 SOUZA, K, M. J. et al . Atraso no diagnóstico da tuberculose em sistema prisional: a experiência do doente apenado. Texto contexto - enferm., Florianópolis , v. 21, n. 1, p. 17-25, mar. 2012.

TFOUNI, F. E. V.; PEREIRA, A. C. Entre o acontecimento e a memória: discursos sobre o papa Francisco em capas de revista de grande circulação. Linguagem em (Dis)curso, v. 16, n. 1, p. 11-33, 2016.

TFOUNI, L. V. Letramento e alfabetização. São Paulo: Cortez, 2010.

. O dado como indício e a contextualização: Do (a) pesquisador nos estudos sobre compreensão da linguagem. D.E.L.T.A., v. 8, n. 2, p. 205-223.1992.

VANIER, A. Lacan. São Paulo: Estação Liberdade, 2005.

\section{Notas}

1 Recuperado de: http://sao-paulo.estadao.com.br/blogs/diego-zanchetta/wp-content/uploads/sites/142/2013/07/dengue.jpg. Acesso em 27/4/2017. Ver também: http://www.prefeitura.sp.gov.br/ cidade/secretarias/upload/pode\%20ser\%20dengue\%20verso\%20arquivo_1253564810.bmp. Acesso em 12/9/2017.

${ }^{2}$ Disponível em: http://www.geraldojose.com.br/ckfinder/userfiles/images/Dengue.jpg. Acesso em 27/4/2017.

${ }^{3}$ Esta campanha foi utilizada pela prefeitura de Cocalzinho de Goiás. Publicado em 8 de janeiro de 2016 por Prefeitura de Cocalzinho em Secretaria de Saúde ; ver: http://www.cocalzinho.go.gov. $\mathrm{br} /$ ?p=12531. Acesso em 12/9/2017

${ }^{4}$ Disponível em: http://cartaototalmed.com.br/Noticias/visualizar/17. Acesso em: 23/6/2017. Disponível também em: http://portaloros.blogspot.com.br/2016/06/obitos-com-suspeita-de-chikungunya-sao.html. E em: http://grandesriosparatodos.blogspot.com.br/2015/12/a-secretaria-da-saude-vera-santiago.html. Acesso em: 12/9/2017. https://www.omelhordosuldeminas.com/56897-2/. Fev, 03, 2016. Acesso em: 12/9/2017.

5 Disponível em: http://campanhaaedes.ufrn.br/assets/images/campanha/pecas_aedes_final_4.jpg. Acesso em 28/4/2017 


\section{Abstract}

Speech and meaning in advertising campaigns on "tropical diseases" transmitted by Aedes aegypt

The article presents results of research on the strategies of interpretation by which advertising campaigns delimit a discursive place to the subject-preventive of the tropical diseases transmitted by Aedes aegypti. For this, it mobilizes concepts of French Discourse Analysis, mainly the concepts of imaginary formations, ideology and subject-position. Affiliated to the analysis paradigm, the study analyzes five images and statements conveyed in these campaigns and shows that the place of the subject-preventive is marked by individual culpability, through a disjunctive logic about the responsibility both to the private space and to the public sphere that ignores the more complex sociopolitical conjuncture of its surroundings.

> Keywords: tropical diseases; Aedes aegypti; health promotion; public health; campaign. 